\title{
Staging of Regional Nodes in Pulmonary Malignancies
}

\author{
Mark B. Faries, MD and Donald L. Morton, MD, FACS \\ Department of Surgical Oncology, John Wayne Cancer Institute at Saint John's Health Center, Santa Monica, CA
}

The role of lymphadenectomy in the surgical management of primary lung cancer is controversial. More than half of patients with apparently node-negative non-small cell lung cancer (NSCLC) will die of metastases within 5 years. ${ }^{1}$ Some of this mortality may be due to direct hematogenous dissemination, but much may reflect surgical and/or pathologic approaches that fail to identify tumorcontaining nodes.

Several randomized clinical trials compared complete mediastinal nodal dissection with systematic nodal sampling. Results were mixed; some showed no benefit (but no harm) with complete dissection, whereas others showed improved survival. $^{2-4}$ A Cochrane review in 2005 reported improved survival with a hazard ratio of 0.78 (95\% confidence interval $0.65-0.93, P=0.005$ ), but a subsequent large randomized trial conducted through the American College of Surgeons Cooperative Group found no difference. ${ }^{5,6}$ Current treatment guidelines state that either approach is acceptable, but accurate staging requires assessment of all relevant nodal stations. ${ }^{7}$

Retrospective series have demonstrated that immunohistochemistry (IHC) can detect tumor cells missed by standard pathologic techniques. Chen et al. identified clinically relevant IHC metastases in $38(63 \%)$ of 60 patients whose nodes were tumor-negative by standard pathology. ${ }^{8} \mathrm{Gu}$ et al. and Kubuschok et al. also found decreased survival among NSCLC patients with occult metastases detected by IHC. ${ }^{9,10}$ By contrast, Marchevsky's group reported that survival benefits based on IHC staining would be difficult to demonstrate. ${ }^{11}$ There appears to be room for additional discovery in this area.

Reverse transcriptase-polymerase chain reaction (RT-PCR) can detect tumor signals in nodes that stain negative by

(C) Society of Surgical Oncology 2011

Published Online: 23 November 2011

D. L. Morton, MD, FACS

e-mail: mortond@jwci.org
IHC. Although critics of nodal IHC may be tempted to extend their objections to nodal RT-PCR, this molecular assay could prove more useful than IHC. In colon cancer, IHC staining of nodes in pNO cases was not helpful, but PCR analysis was. ${ }^{12}$ Indeed, in NSCLC, Benlloch et al. demonstrated prognostic significance of molecular metastases. ${ }^{13}$ Furthermore, Hashimoto et al. showed that RT-PCR detection of tumor-specific molecular markers was prognostic, while staining by IHC was not independently so. ${ }^{14}$

Enhanced pathologic evaluation of lymph nodes by IHC or RT-PCR probably will improve staging in NCSLC but is unlikely to be practical for all nodes removed in a complete nodal dissection. ${ }^{15}$ However, lymphatic mapping of the sentinel lymph node (SLN) can yield a nodal specimen whose tumor status reflects the entire basin. If laborintensive evaluations such as IHC or RT-PCR are limited to this small sample, they become much more feasible. In melanoma and breast cancer, SLN mapping is feasible and reliable when performed by a team with appropriate experience. ${ }^{16}$ In NSCLC, this has not been uniformly true.

Little et al. and Liptay et al. reported SLN identification rates of $47 \%$ and $82 \%$, respectively, in early experiences with lymphatic mapping for NSCLC. ${ }^{17,18}$ However, in our 2004 series of 67 patients with pulmonary malignancies, SLN identification rate was $100 \% .^{19}$ More recent reports confirm variable rates of SLN identification. In the CALGB 140203 trial, SLN mapping had an accuracy of $51.3 \%$ and an identification rate of only $61.5 \% .^{20}$

Why are the results of SLN mapping in the lung so inconsistent? It is probably a reflection of chest-specific technical difficulties. Nodes are close to the injection site, and their mapping is further complicated by the confined geometry of the thoracic cage and by the carbon pigment that naturally accumulates in lymph nodes draining the lung. Proposed solutions include use of different visual and radioactive tracers (isosulfan blue, Patent $\mathrm{V}$, methylene blue, indocyanine green, sulfur colloid, nanocolloid, tin 
colloid, phytate, and ferromagnetic particles), several injection strategies (direct injection at thoracotomy, injection via video-assisted thoracoscopic surgery, computed tomography-guided transthoracic injection and bronchoscopic injection), and alternate surgical mapping procedures (in vivo, ex vivo, or combined) ${ }^{18-28}$ At this point, there does not seem to be an obvious winner, but the level of interest in these technologies speaks to the potential importance of nodal mapping to the field.

In this issue of Annals of Surgical Oncology, Yamashita and colleagues report innovations in both surgical and pathologic aspects of the mapping technique. ${ }^{29}$ They used indocyanine green as a mapping agent because this dye fluoresces in the near-infrared and can be visualized with an intraoperative imaging system, even in carbon-stained nodes. However, the close proximity of the injection site still caused several failed mapping procedures. They addressed this problem with technical modifications in later cases, and their reasonable identification rate of $80.3 \%$ should continue to improve.

They also used quantitative RT-PCR to detect cytokeratin-19 mRNA. Because the number of patients with PCRpositive lymph nodes is small and the follow up still relatively short, the clinical significance of these data remain undetermined. There are potential concerns with the particular technical procedure that was used. These include the sacrifice of half of the nodal tissue for analysis and the use of a single keratin marker, which could be affected by the presence of translocated, nonmalignant cells. In recent years techniques have become available to molecularly evaluate fixed, paraffin-embedded tissues. ${ }^{30}$ This allows for normal pathologic processing of the nodes before molecular analysis. The use of multiple markers or markers specific for malignancy may further improve the clinical relevance of the technique.

Overall, this report underlines the ongoing interest in nodal staging of NSCLC. Innovations in surgical techniques, pathologic evaluation and possibly imaging will help us identify SLNs and determine the significance of nodal micrometastases.

ACKNOWLEDGMENT Supported by grants P01 CA29605 and P01 CA12582 from the National Cancer Institute and by funding from the Dr. Miriam and Sheldon G. Adelson Medical Research Foundation (Boston, MA) and the Melanoma Research Alliance (Washington, DC). The content is solely the responsibility of the authors and does not necessarily represent the official view of the National Cancer Institute or the National Institutes of Health.

\section{REFERENCES}

1. SEER. SEER Cancer Statistics Review. Lung and bronchus, 1975-2000. http://seer.cancer.gov/csr/1975_2000/sections.html

2. Izbicki JR, Passlick B, Pantel K, et al. Effectiveness of radical systematic mediastinal lymphadenectomy in patients with resectable non-small cell lung cancer: results of a prospective randomized trial. Ann Surg. 1998;227:138-44.

3. Sugi $K$, Nawata K, Fujita $N$, et al. Systematic lymph node dissection for clinically diagnosed peripheral non-small-cell lung cancer less than $2 \mathrm{~cm}$ in diameter. World J Surg. 1998; 22:290-4.

4. Wu Y, Huang ZF, Wang SY, et al. A randomized trial of systematic nodal dissection in resectable non-small cell lung cancer. Lung Cancer. 2002;36:1-6.

5. Manser R, Wright G, Hart D, et al. Surgery for early stage nonsmall cell lung cancer. Cochrane Database Syst Rev. 2005; (1):CD004699.

6. Allen MS, Darling GE, Pechet TT, et al. Morbidity and mortality of major pulmonary resections in patients with early-stage lung cancer: initial results of the randomized, prospective ACOSOG Z0030 trial. Ann Thorac Surg. 2006;81:1013-9.

7. Scott WJ, Howington J, Feigenberg S, et al. Treatment of nonsmall cell lung cancer stage I and stage II: ACCP evidencebased clinical practice guidelines (2nd edition). Chest. 2007; 132(3 Suppl):234S-42S.

8. Chen Z, Perez S, Holmes E, et al. Frequency and distribution of occult micrometastases in lymph nodes of patients with nonsmall-cell lung carcinoma. J Natl Cancer Inst. 1993;85:493-8.

9. Gu C, Osaki T, Oyama T, et al. Detection of micrometastatic tumor cells in pNO lymph nodes of patients with completely resected nonsmall cell lung cancer: impact on recurrence and survival. Ann Surg. 2002;235:133-9.

10. Kubuschok B, Passlick B, Izbicki JR, et al. Disseminated tumor cells in lymph nodes as a determinant for survival in surgically resected non-small-cell lung cancer. J Clin Oncol. 1999; 17:19-24.

11. Marchevsky AM, Gupta R, Kusuanco D, et al. The presence of isolated tumor cells and micrometastases in the intrathoracic lymph nodes of patients with lung cancer is not associated with decreased survival. Hum Pathol. 2010;41:1536-43.

12. Iddings D, Bilchik A. The biologic significance of micrometastatic disease and sentinel lymph node technology on colorectal cancer. J Surg Oncol. 2007;96:671-7.

13. Benlloch S, Galbis-Caravajal JM, Alenda C, et al. Expression of molecular markers in mediastinal nodes from resected stage I non-small-cell lung cancer (NSCLC): prognostic impact and potential role as markers of occult micrometastases. Ann Oncol. 2009;20:91-7.

14. Hashimoto T, Kobayashi Y, Ishikawa Y, et al. Prognostic value of genetically diagnosed lymph node micrometastasis in nonsmall cell lung carcinoma cases. Cancer Res. 2000;60:6472-8.

15. Goldstein N, Mani A, Chmielewski G, et al. Immunohistochemically detected micrometastases in peribronchial and mediastinal lymph nodes from patients with T1, N0, M0 pulmonary adenocarcinomas. Am J Surg Pathol. 2000;241:274-9.

16. Morton DL, Thompson JF, Cochran AJ, et al. Sentinel-node biopsy or observation in melanoma. $N$ Engl J Med. 2006; 355:1307-17.

17. Little A, DeHoyos A, Kirgan D, et al. Intraoperative lymphatic mapping for non-small cell lung cancer: the sentinel node technique. J Thorac Cardiovasc Surg. 1999;117:220-34.

18. Liptay M, Masters G, Winchester D, et al. Intraoperative radioisotope sentinel node mapping in non-small cell lung cancer. Ann Thor Surg. 2000;70:384-9.

19. Faries MB, Bleicher RJ, Ye X, et al. Lymphatic mapping and sentinel lymphadenectomy for primary and metastatic pulmonary malignant neoplasms. Arch Surg. 2004;139:870-6.

20. Liptay MJ, D'Amico T A, Nwogu C, et al. Intraoperative sentinel node mapping with technitium-99 in lung cancer: results of CALGB 140203 multicenter phase II trial. J Thorac Oncol. 2009; z4:198-202. 
21. Bustos ME, Camargo JJ, Resin Geyer G, et al. Intraoperative detection of sentinel lymph nodes using Patent Blue V in nonsmall cell lung cancer. Minerva Chir. 2008;63:29-36.

22. Rzyman W, Hagen OM, Dziadziuszko R, et al. Blue-dye intraoperative sentinel lymph node mapping in early non-small cell lung cancer. Eur J Surg Oncol. 2006;32:462-5.

23. Ito N, Fukuta M, Tokushima T, et al. Sentinel node navigation surgery using indocyanine green in patients with lung cancer. Surg Today. 2004;34:581-5.

24. Melfi FM, Lucchi M, Davini F, et al. Intraoperative sentinel lymph node mapping in stage I non-small cell lung cancer: detection of micrometastases by polymerase chain reaction. Eur $J$ Cardiothorac Surg. 2008;34:181-6.

25. Nomori H, Horio H, Naruke T, et al. Use of technetium- $99 \mathrm{~m}$ tin colloid for sentinel lymph node identification in non-small cell lung cancer. J Thorac Cardiovasc Surg. 2002;124:486-92.

26. Nomori H, Ohba Y, Yoshimoto K, et al. Difference of sentinel lymph node identification between tin colloid and phytate in patients with non-small cell lung cancer. Ann Thorac Surg. 2009; 87:906-10.

27. Minamiya $\mathrm{Y}$, Ito $\mathrm{M}$, Katayose $\mathrm{Y}$, et al. Intraoperative sentinel lymph node mapping using a new sterilizable magnetometer in patients with nonsmall cell lung cancer. Ann Thorac Surg. 2006;81:327-30.

28. Lardinois D, Brack T, Gaspert A, et al. Bronchoscopic radioisotope injection for sentinel lymph-node mapping in potentially resectable non-small-cell lung cancer. Eur J Cardiothorac Surg. 2003;23:824-7.

29. Yamashita S, Tokuishi K, Miyawaki M, et al. Sentinel node navigation surgery by thoracoscopic fluorescence imaging system and molecular examination in non-small cell lung cancer. Ann Surg Oncol. doi:10.1245/s10434-011-2145-x.

30. Takeuchi H, Morton DL, Kuo C, et al. Prognostic significance of molecular upstaging of paraffin-embedded sentinel lymph nodes in melanoma patients. J Clin Oncol. 2004;22: 2671-80. 